\title{
Intraoperative Hypotension: Immediate and Short Term Impact on Mortality. Findings from a High Dependency Cardiac and Vascular Surgical Center in Nigeria
}

\author{
Peter K. Uduagbamen ${ }^{* 1}$, Michael Sanusi², Olumide B. Udom², Sule I. Ahmed, Osaze Ehioghae ${ }^{1}$, \\ Olutomiwa A. Omokore ${ }^{1}$ \\ ${ }^{1}$ Division of Nephrology and Hypertension, Department of Internal Medicine, Ben Carson (Snr) School of Medicine, Babcock \\ University/ Babcock University Teaching Hospital, Ilishan-Remo, Nigeria.
}

${ }^{2}$ Tristate Heart and Vascular Centre, Babcock University/Babcock University Teaching Hospital, Ilishan-Remo, Nigeria.

${ }^{3}$ Orthopedic and Trauma Unit, Department of Surgery, Asokoro District Hospital, HMB, FCT, Abuja, Nigeria.

\begin{abstract}
Introduction: Intraoperative hypotension in cardiac surgery could be complicated by acute kidney injury (AKI), cardiac arrest and death due to poor organ perfusion. We studied intraoperative hypotension (IOH) and its immediate and short term relationship with post-operative mortality.
\end{abstract}

Materials \& Methods: A retrospective study of participants, 16-86 years old who underwent cardiac and vascular surgery at Tristate Heart and Vascular Center, Ilishan-Remo, Nigeria, a high dependency cardiac and vascular surgical center between January 2015 and March 2021. Study participants were grouped into three cohorts and primary outcome was all-cause post-operative death.

Results: The records of four hundred and fifteen (258 males and 157 females) cohorts were studied, with mean age of $56.6 \pm 5.4$ years, $14.69 \%$ of the participants were 65 years or older. The surgeries were coronary artery bypass graft (CABG) alone (26.03\%), CABG with valve surgery $(38.31 \%)$ and, valves surgery alone $(35.66 \%)$. The mean arterial pressure (MAP) pre-induction, and intra-operative and immediate post-op were $71.37 \pm 1409 \mathrm{mmHg}, 68.6 \pm 11.24 \mathrm{mmHg}$ and $72.24 \pm 33 \mathrm{mmHg}$ respectively. The incidence of IOH was $86.30 \%$, prevalence of background kidney dysfunction was $29.40 \%$ and incidence of AKI was $25.54 \%$. Eleven (2.65\%) participants died, all (100\%) had IOH, 1 $(9.09 \%)$ was intradialytic. The predictors of mortality were aging (aOR-4.23, 1.65-5.85), IOH (aOR-1.55, CI-0.34-1.96), background kidney disease (aOR-3.96, CI-1.43-4.78), comorbidity (aOR-2.77, CI-0.87-3.17), emergency surgery (aOR-4.62, CI-1.35-5.12), pre-induction MAP (aOR-4.22, CI-3.15-6.49) and, combined CABG and valve surgery (aOR-2.17, CI-1.69-4.57)).

Conclusion: Intraoperative hypotension commonly results from cardiac and vascular surgeries and could be complicated by AKI, cardiac arrest and death. The risk of these complications is increased by background kidney disease, comorbidities and episodes of IOH.

Keywords: Intraoperative hypotension, Coronary artery bypass graft, Acute kidney injury, Cardiac arrest, Mortality, Mean arterial pressure.

\section{INTRODUCTION}

Arterial hypotension under anesthesia during cardiac and vascular surgery (CVS) is common and is established to be complicated by poor treatment outcome encompassing single or multi organ dysfunction, and death [1]. Arterial blood pressure, commonly the mean arterial pressure (MAP) in the lower range would cause low cardiac output and poor organ perfusion, and when lower than vascular auto regulation, particularly if prolonged, could lead to ischemic injury in organ-systems and could be complicated by acute kidney injury (AKI), cardiovascular and neurological dysfunction [2].

Despite the wide variability in incidence of intraoperative hypotension $(\mathrm{IOH})$, occasioned by several diagnostic criteria,

*Address correspondence to this author at the Division of Nephrology and Hypertension, Department of Internal Medicine, Ben Carson (Snr) School of Medicine, Babcock University/ Babcock University Teaching Hospital, Ilishan-Remo, Nigeria. Email: petr.uduagbamen@gmail.com mortality from cardiac surgery secondary to $\mathrm{IOH}$, occurring up to 30 days postop is well established, and is reported to be related to patients' baseline health status and intraoperative events [3]. Within a risk level, treatment outcome is affected by wide variations in intraoperative systolic blood pressure (SBP) [4] just as the time of occurrence of $\mathrm{IOH}$ also determines the pathophysiologic mechanisms and perhaps the management strategies [5].

Even in advance nations, $\mathrm{IOH}$ from cardiac surgeries are less studied compared to non-cardiac surgeries. Cardiac surgeries are quite expensive, unaffordable to the less privileged, and this contributes to the scares literature in sub-Sahara Africa (SSA) [6]. Considering these limitations in low income nations (LINs), it would be expected that the true incidence of $\mathrm{IOH}$ in them would be higher but the relative poor blood pressure control in this population could be beneficial. We hypothesize that $\mathrm{IOH}$ is quite common and could be compli- 
cated by organ system dysfunction and death. We studied intraoperative hypotension and its immediate and short term impact on post-operative mortality in participants who underwent cardiac and vascular surgery.

\section{MATERIALS AND METHODS}

Study Design: This retrospective observational study was conducted at the Tristate Heart and Vascular Surgical Centre, Ilishan-Remo, a teaching hospital in Nigeria. Participants who had cardiac and/or major vascular surgery between January 2015 and March 2021 were studied. Participants' records were grouped into 3: those who had coronary artery bypass graft (CABG) alone, single or multiple valve surgery, or CABG plus valve surgery. All CABG were on-pump.

Data Collection: Participants' data (415) were retrieved from the center's data base, case notes, perioperative charts and intensive care unit (ICU) charts. Their sociodemographics, presenting complaints, history of hypertension, cardiac/renal/central nervous system disease were documented. History related to the cardiac diseases that were retrieved included: elective/emergency, duration, previous cardiac surgical procedures, post-operative sepsis, comorbidities, and duration of hospital stay until discharge or death. Physical examination findings retrieved included body mass index (BMI), percent oxygen saturation $\left(\mathrm{SPO}_{2}\right)$ mean arterial pressures (MAP) and heart rate (HR). Investigation results retrieved included urinalysis, bed side arterial blood gases (ABGs), serum electrolyte, urea, creatinine, albumin and uric acid, GFR, full blood count (FBC), blood glucose, fasting lipids and daily fluid charts.

Exclusion Criteria: Participants $<16$ years, with previous surgery 30 days prior to index surgery, repeat surgeries for same condition, end stage kidney disease (ESKD), brain death, and death within 24 hours post-surgery were excluded, including patients with organ transplant, off pump $C A B G$ and patients with ventricular assist devices.

\section{DEFINITIONS}

Mean Arterial Pressure (MAP): Diastolic BP plus a third of the pulse pressure (PP) [2].

Intraoperative Hypotension: MAP $<65 \mathrm{mmHg}$ for more than 5 minutes [3].

Hypoalbuminemia: Serum albumin $<35.0 \mathrm{mg} / \mathrm{dL}$ [7].

Anemia: Hematocrit $<33.0 \%$ [8].

\section{STATISTICAL ANALYSIS}

The Statistical Package for Social Sciences (SPSS) version 22.0 (IBM Inc, NY, USA) was used in data analysis. Continuous variables were presented as means with standard deviation or medians with range and compared using paired t-test. Categorical variables were presented as proportions and compared using the Chi-square test or Fisher's exact test, where less than five observations were recorded. Multivariate analyses were used to determine independent predictors of post-operative mortality. Variables with a P-value of $<0.25$ on univariate analysis were entered into multivariate regression model to determine independent predictors of mortality with backward elimination to adjust for confounders [9]. A significance level of $p<0.05$ was considered in the final regression model.

\section{ETHICAL CLEARANCE}

The Babcock University Human Research Ethics Committee (BUHREC) approved the study (BUHREC558/19, NHREC/24/01/2018) but waived obtaining participants consent.

\section{RESULTS}

One hundred and eight (26.03\%) patients with a mean age of $63.37 \pm 7.42$ years had CABG alone, $148(35.66 \%)$ with a mean age of $51.85 \pm 7.59$ years had valve surgeries alone and, $159(38.31 \%)$ with a mean age of $56.66 \pm 6.40$ had combined $\mathrm{CABG}$ and valve surgeries. The mean age of the participants was $56.69 \pm 5.47$ years, $14.69 \%$ of the surgeries were for participants 65 years or older (Table 1). The commonest presenting complaint was dyspnea $(38.42 \%)$, followed by chest pain (21.58\%), poor exercise tolerance (19.22\%), others $(20.78 \%)$.

Table 1. Characteristics of the Study Population.

\begin{tabular}{|l|l|}
\hline Variables & Frequency (\%)/Mean (SD) \\
\hline Sex & $258(62.20)$ \\
Males & $157(37.80)$ \\
Females & $56.6 \pm 5.4$ \\
\hline Ages, Years, Mean & $354(85.3)$ \\
$<65$ & $61(14.7)$ \\
$\geq 65$ & $112(27.0)$ \\
\hline Primary Cardiac Diseases & $193(46.50)$ \\
Coronary Artery Disease & $34(8.19)$ \\
Vavular Disease & $76(18.31)$ \\
Dilated Cardiomyopathy & \\
Others & $74(17.83)$ \\
\hline Mode of Surgery & $341(82.17)$ \\
Emergency & \\
Elective & $108(26.03)$ \\
\hline Surgery Type & $148(35.66)$ \\
CABG & $159(38.31)$ \\
Valve & \\
CABG and Valves & \\
\hline
\end{tabular}

CABG: Coronary artery bypass graft. 
Of the 154 participants that had at least one comorbidity, 58 (37.66\%) had CABG alone, 33 (21.43\%) had valve surgery alone and, 63 (40.91\%) had combined CABG and valve surgery (Table 2). One hundred and twenty two $(29.40 \%)$ participants had background kidney dysfunction, 44 (36.06\%) of these had AKI. Of the remaining 293 without background
KD, 58 (19.80\%) had AKI, $\mathrm{P}<0.001$. A hundred and two $(30.2 \%)$ participants had hypertension of which $72(76.6 \%)$ were receiving diuretic therapy prior to surgery. Twenty-two $(7.1 \%)$ had diabetes and $8(2.6 \%)$ had liver disease. The mean pre-induction GFR was $72.2 \pm 8.3 \mathrm{ml} / \mathrm{min} / 1.73 \mathrm{~m}^{2}$.

Table 2. History and Baseline Clinical Findings in Study Population.

\begin{tabular}{|c|c|c|c|c|c|}
\hline Variables & $\begin{array}{l}\text { All Cohorts } \\
\mathrm{N}=415(\%) \\
\text { Mean } \pm \text { SD }\end{array}$ & $\begin{array}{c}\text { CABG } \\
\mathrm{N}=108(\%) \\
\text { Mean } \pm \mathrm{SD}\end{array}$ & $\begin{array}{c}\text { Valve Surgery } \\
\mathrm{N}=148(\%) \\
\text { Mean } \pm \mathrm{SD}\end{array}$ & $\begin{array}{c}\text { CABG Plus valve } \\
\begin{array}{c}\mathrm{N}=159(\%) \\
\text { Mean } \pm \text { SD }\end{array}\end{array}$ & P-value \\
\hline \multicolumn{6}{|l|}{ Sex } \\
\hline Males & $258(62.20)$ & $82(75.90)$ & $99(66.90)$ & $77(44.4)$ & $0.038 *$ \\
\hline Females & $157(37.80)$ & $26(24.10)$ & $40(33.10)$ & $82(55.6)$ & \\
\hline Age, Years & $56.69 \pm 5.47$ & $63.37 \pm 7.42$ & $51.85 \pm 7.59$ & $56.66 \pm 6.40$ & 0.051 \\
\hline \multicolumn{6}{|l|}{ Pre-induction MAP, $\mathrm{mmHg}$} \\
\hline Mean & $71.37 \pm 1409$ & $74.38 \pm 9.68$ & $69.02 \pm 11.42$ & $71.49 \pm 10.36$ & $0.042 *$ \\
\hline$<70$ & $59(14.21)$ & $8(7.41)$ & $33(22.30)$ & $18(11.32)$ & $0.046 *$ \\
\hline$\geq 70$ & $356(85.79)$ & $100(92.59)$ & $115(77.70)$ & $141(88.68)$ & \\
\hline Preoperative eGFR, ml/min, & $72.2 \pm 8.3$ & $67.28 \pm 6.42$ & $74.23 \pm 9.22$ & $73.62 \pm 6.39$ & $0.001 *$ \\
\hline Preinduction sodium, mmol/L & $136.34 \pm 12.1$ & $136.87 \pm 13.55$ & $135.44 \pm 11.73$ & $136.41 \pm 10.85$ & 0.069 \\
\hline Pre-induction bicarbonate, $\mathrm{mmol} / \mathrm{L}$ & $22.57 \pm 5.62$ & $23.16 \pm 7.36$ & $21.94 \pm 7.11$ & $22.66 \pm 9.42$ & 0.055 \\
\hline Pre-induction anion gap, $\mathrm{mEq} / \mathrm{L}$ & $15.95 \pm 6.82$ & $15.21 \pm 9.48$ & $16.05 \pm 7.02$ & $16.30 \pm 8.43$ & $0.041 *$ \\
\hline Pre-induction albumin & $36.16 \pm 7.33$ & $35.83 \pm 6.71$ & $37.05 \pm 7.56$ & $35.55 \pm 8.14$ & 0.064 \\
\hline Preoperative hematocrit, $\%$ & $36.72 \pm 6.38$ & $34.89 \pm 5.64$ & $37.98 \pm 5.75$ & $35.53 \pm 7.78$ & $0.004 *$ \\
\hline
\end{tabular}

*Statistical significance, CABG: Coronary artery bypass graft, MAP: Mean arterial pressure, eGFR: Estimated glomerular filtration rate.

Table 3. Relationship between Participants' Characteristics and Intraoperative Hypotension.

\begin{tabular}{|c|c|c|c|}
\hline Variables & $\begin{array}{c}\text { No IOH } \\
\text { MAP }<65 \mathrm{mmHg} \\
\leq 5 \text { minutes }->65 \mathrm{mmHg} \mathrm{N}=57(\%)\end{array}$ & $\begin{array}{c}\text { IOH } \\
\text { MAP }<65 \mathrm{mmHg}> \\
>5 \text { minutes } \mathrm{N}=358(\%)\end{array}$ & P-value \\
\hline $\begin{array}{l}\text { Surgical Modality } \\
\text { Emergency } \\
\text { Elective }\end{array}$ & $\begin{array}{c}4(5.41) \\
53(15.54)\end{array}$ & $\begin{array}{c}70(94.59) \\
288(84.46)\end{array}$ & $0.003 *$ \\
\hline $\begin{array}{l}\text { Surgery Duration, Hour } \\
<3 \\
\geq 3\end{array}$ & $\begin{array}{l}22(22.68) \\
35(11.00)\end{array}$ & $\begin{array}{c}75(77.32) \\
283(89.00)\end{array}$ & $0.002 *$ \\
\hline $\begin{array}{l}\text { Intraop Vasopressors/Inotropes } \\
\text { None } \\
\text { Yes }\end{array}$ & $\begin{array}{c}51(17.68) \\
6(4.69)\end{array}$ & $\begin{array}{l}236(82.32) \\
122(95.31)\end{array}$ & $0.001 *$ \\
\hline $\begin{array}{l}\text { Postop Vasopressors/Inotropes } \\
\text { None } \\
\text { Yes } \\
\end{array}$ & $\begin{array}{c}55(20.60) \\
2(1.35) \\
\end{array}$ & $\begin{array}{l}212(79.40) \\
146(98.65) \\
\end{array}$ & $<0.001 *$ \\
\hline Surgery Cohorts & $\mathrm{N}=57(\%)$ & $\mathrm{N}=358(\%)$ & \\
\hline $\begin{array}{l}\text { CABG Alone } \\
\text { VS alone plus (combined CABG }+ \text { VS) }\end{array}$ & $\begin{array}{c}8(7.41) \\
49(15.96)\end{array}$ & $\begin{array}{l}100(92.59) \\
258(84.04)\end{array}$ & $0.003 *$ \\
\hline $\begin{array}{l}\text { VS Alone } \\
\text { CABG alone plus (combined CABG }+\mathrm{VS} \text { ) }\end{array}$ & $\begin{array}{l}19(12.84) \\
38(14.23)\end{array}$ & $\begin{array}{l}129(87.16) \\
229(85.77)\end{array}$ & $0.042 *$ \\
\hline $\begin{array}{l}\text { Combined } \mathrm{CABG} \text { and } \mathrm{VS} \\
\mathrm{CABG} \text { alone plus VS alone }\end{array}$ & $\begin{array}{l}30(18.87) \\
27(10.55)\end{array}$ & $\begin{array}{l}129(81.13) \\
229(89.45)\end{array}$ & $0.002 *$ \\
\hline
\end{tabular}

*Statistical significance, CABG: Coronary artery bypass graft, VS: Valve surgery. 
The Mean Arterial Pressure (MAP) pre-induction, intra-operative and immediate post-op were $71.37 \pm 1409 \mathrm{mmHg}, 68.6$ $\pm 11.24 \mathrm{mmHg}$ and $72.24 \pm 33 \mathrm{mmHg}, \mathrm{P}=0.03$. The incidence of one, and multiple episodes of IOH were $86.30 \%$ (Table 3 ) and $65.75 \%$ respectively. The incidence of cumulative AKI was $25.54 \%$. Eleven $(2.65 \%)$ died in the course of treatment, all $(100 \%)$ had at least an episode of IOH while $7(63.63 \%)$ had multiple episodes of $\mathrm{IOH}$. One $(9.09 \%)$ of the death occurred intradialysis from cardiac arrest associated with intradialysis hypertension. Of the 11 (6 males and 5 females) deaths, $3(27.27 \%)$ were within post op day 3 (POD3), 1 (9.09\%) died between POD3 and POD7, and the remaining 7 (63.63\%) died after POD28. Of the 11 death, 7 (63.64\%) were 65 years or older, $8(72.72 \%)$ had background kidney dysfunction, $7(63.64 \%)$ had perioperative sepsis and 7 $(63.64 \%)$ had emergency surgery. Eight $(72.72 \%)$ of the dead had surgeries lasting more than 3 hours (Table 4). Of the 11 death, 3 (27.27\%) CABG alone, $1(9.09 \%)$ had valve surgery

Table 4. Relationship between Participants' Characteristics and Surgical Outcome.

\begin{tabular}{|c|c|c|c|c|c|}
\hline Variables & $\begin{array}{c}\text { Not deceased } \\
\mathrm{N}=404(\%)\end{array}$ & $\begin{array}{l}\text { Deceased } \\
\mathrm{N}=11(\%)\end{array}$ & OR & $95 \% \mathrm{CI}$ & P-value \\
\hline \multicolumn{6}{|l|}{ Sex } \\
\hline Males & $252(97.67)$ & $6(2.33)$ & \multirow{2}{*}{0.92} & \multirow{2}{*}{$0.15-0.87$} & \multirow{2}{*}{0.093} \\
\hline Females & $152(96.82)$ & $5(3.18)$ & & & \\
\hline \multicolumn{6}{|l|}{ Age, Years } \\
\hline$<65$ & $350(98.87)$ & $4(1.13)$ & \multirow{2}{*}{3.85} & \multirow{2}{*}{$1.78-5.96$} & \multirow{2}{*}{$<0.001^{*}$} \\
\hline$\geq 65$ & $54(88.52)$ & $7(11.48)$ & & & \\
\hline \multicolumn{6}{|l|}{ Comorbidity } \\
\hline None & $260(99.62)$ & $1(0.38)$ & \multirow{2}{*}{2.36} & \multirow{2}{*}{$1.99-3.72$} & \multirow{2}{*}{$0.022 *$} \\
\hline$\geq 1$ & $144(93.51)$ & $10(6.49)$ & & & \\
\hline \multicolumn{6}{|l|}{ Background Kidney Dysfunction } \\
\hline eGFR $<60$ & $111(90.98)$ & $11(9.02)$ & \multirow[b]{2}{*}{5.48} & \multirow[b]{2}{*}{$1.67-6.81$} & \multirow{2}{*}{$<0.001^{*}$} \\
\hline $\mathrm{eGFR} \geq 60$ & $293(100.0)$ & $0(0.0)$ & & & \\
\hline \multicolumn{6}{|l|}{ Surgical Modality } \\
\hline Emergency & $64(86.49)$ & $10(13.51)$ & \multirow[b]{2}{*}{4.32} & \multirow{2}{*}{$2.86-6.39$} & \multirow[b]{2}{*}{$<0.001^{*}$} \\
\hline Elective & $340(99.71)$ & $1(0.29)$ & & & \\
\hline \multicolumn{6}{|l|}{ Pre-Induction MAP, mmHg } \\
\hline$<70$ & $51(86.44)$ & $8(13.56)$ & \multirow[b]{2}{*}{3.93} & \multirow{2}{*}{$3.17-4.92$} & \multirow{2}{*}{$<0.001^{*}$} \\
\hline$\geq 70$ & $353(99.16)$ & $3(0.84)$ & & & \\
\hline \multicolumn{6}{|l|}{ Intraoperative Hypotension, $\mathrm{mmHg}$} \\
\hline None & $56(100.0)$ & $0(0.0)$ & \multirow[b]{2}{*}{2.41} & \multirow{2}{*}{$0.54-2.43$} & \\
\hline Yes & $348(96.93)$ & $11(3.07)$ & & & $0.003^{*}$ \\
\hline Intraoperative Vasopressors/Inotropes & & & & & \\
\hline None & $285(99.30)$ & $2(0.70)$ & & & \\
\hline Yes & $119(92.97)$ & $9(7.03)$ & 2.57 & $2.03-4.05$ & $0.003^{*}$ \\
\hline Surgery Duration, Hours & & & & & \\
\hline$<3$ & $96(98.97)$ & $1(1.03)$ & & & \\
\hline$\geq 3$ & $308(96.85)$ & $10(3.15)$ & 1.5 & $1.0-2.86$ & $0.046^{*}$ \\
\hline Postoperative Vasopressors/Inotropes & & & & & \\
\hline None & $262(98.13)$ & $5(1.87)$ & & & \\
\hline Yes & $142(95.95)$ & $6(4.05)$ & 1.1 & $0.74-1.53$ & 0.064 \\
\hline Surgery Cohorts & & & & & \\
\hline CABG alone & $105(97.22)$ & $3(2.78)$ & & & \\
\hline Valve alone plus (CABG + valve surgery) & $299(97.39)$ & $8(2.61)$ & 0.8 & $0.69-1.22$ & 0.600 \\
\hline Valve surgery alone & $147(99.32)$ & $1(0.68)$ & & & \\
\hline CABG alone plus combined CABG + Valve surgery & $257(96.25)$ & $10(3.75)$ & 2.44 & $1.05-3.98$ & *0.027 \\
\hline Combined CABG and Valve surgery & $152(95.60)$ & $7(4.40)$ & & & \\
\hline CABG alone plus Valve surgery alone & $252(98.44)$ & $4(1.56)$ & 2.41 & $1.45-4.72$ & $0.020^{*}$ \\
\hline
\end{tabular}

CI: Confidence interval, OR: Odd ratio, Ref: Reference category, *Statistical significance, GFR: Glomerular filtration rate, MAP: Mean arterial pressure, CABG: Coronary artery bypass graft. 
alone while $7(63.63 \%)$ had combined CABG and valve surgery.

With multivariate analysis (Table 5), aging (aOR-4.23,
CI-1.65-5.85), comorbidity (aOR-2.77, CI-0.87-3.17), background kidney dysfunction (aOR-3.96, CI-1.43-4.78), emergency surgery (aOR-4.62, CI-1.35-5.12), pre-induction MAP (aOR-4.22, CI-3.15-6.49), intraoperative hypotension

Table 5. Multivariate Regression Analysis.

\begin{tabular}{|c|c|c|c|}
\hline Variables & aOR & $95 \% \mathrm{CI}$ & P-value \\
\hline Aging & 4.23 & $1.65-5.85$ & $<0.001 *$ \\
\hline Comorbidity & 2.77 & $0.87-3.17$ & $0.004 *$ \\
\hline Background kidney dysfunction & 3.96 & $1.43-4.78$ & $0.001 *$ \\
\hline Surgical modality & 4.62 & $1.35-5.12$ & $<0.001^{*}$ \\
\hline Pre-induction MAP, $\mathrm{mmHg}$ & 4.22 & $3.15-6.49$ & $<0.001 *$ \\
\hline Intraoperative hypotension & 1.65 & $0.34-1.96$ & $0.045^{*}$ \\
\hline Intraoperative vasopressors/inotropes & 1.25 & $1.16-1.92$ & 0.066 \\
\hline \multicolumn{4}{|l|}{ Surgery Cohorts } \\
\hline CABG alone & 1.08 & $0.94-1.53$ & 0.080 \\
\hline Valve surgery alone & 1.33 & $1.23-3.01$ & 0.057 \\
\hline Combined valve surgery + CABG & 2.17 & $1.69-4.51$ & $0.034^{*}$ \\
\hline
\end{tabular}

*Statistical significance, MAP: Mean arterial pressure, CABG: Coronary artery bypass graft.

(aOR-1.55, CI-0.34-1.96) and, combined CABG and valve surgery (aOR-2.17, CI-1.69-4.57) independently predicted postoperative mortality.

\section{DISCUSSION}

The incidence of intraoperative hypotension, and post-operative mortality were $86.30 \%$ and $65.75 \%$ respectively. The prevalence of preoperative kidney dysfunction was $29.40 \%$ while the incidence of cumulative post-operative AKI was $25.54 \%$. The incidence of $86.30 \%$ is very close to the $88 \%$ found by Shah et al. [10] using a threshold MAP $<65 \mathrm{mmHg}$ for more than a minute, as against 5 minutes used in this study. It falls within the 5-99\% generally reported, and within the $83.2-91.6 \%$ and $41-93 \%$ incidence respectively reported by the same authors in systematic reviews of mortalities associated with $\mathrm{IOH}$ induced by cardiac surgery. The wide variability in the diagnostic criteria and definitions of $\mathrm{IOH}$ is responsible for these wide variability in incidence rates [11, $12]$.

The incidence of post cardiac surgery mortality (PCSM) in our study agrees with findings by Shahian et al. [13] who reported a 30 -day in-hospital mortality of $2.3 \%$ in patients who had CABG, and the $3.4 \%$ found by O'biene et al. [14] who found an incidence of $3.4 \%$ in patients who underwent lone cardiac valvular surgeries. Mazzenffi et al. [15] also found an incidence of $3.4 \%$ amongst patients with cardiac surgeries, similar to our findings. Hypotension during cardiac surgery could be multifactorial: from arrhythmias such as atrial fibrillation, cardiac manipulation, poor left ventricular function and reduction in systemic resistance occasioned by the use of anesthetic agents [16]. Intraoperative hypotension, particularly if prolonged, disrupt the auto regulatory mechanisms of several organ-systems like the brain, heart and kidneys. Prolonged ischemia with reperfusion injury associated with multi-organ dysfunctional state (MODS) could cause the release of cytotoxic cytokines which exacerbate the injurious process and could lead to death [17].

Though similar incidence, the slightly lower rate in our study compared to the developed world is not necessarily a pointer to better management, but the fact that centers is low income settings like ours, been fully aware of some limitations on their part, tend to be more selective in patient recruitment for elective surgeries, and engage more profound patient preparations. Another factor responsible for the slightly lower incidences in our settings is the relative poor blood pressure control in our clime [18]. African Americans (AAs) that carry similar genetic identity to our study population, are known to have higher blood pressure than other ethnic and racial groups in the United States [19]. Also, the control of hypertension, its complications and associated comorbidities in these AAs is known to be more cumbersome. The identification of the pathogenetic role of the Apolipoprotein LI (APOL1) risk variants in AAs and, genetically, our study cohorts, further explains this seemingly paradox [20].

The higher incidence of PCSM in the elderly is in agreement with previous findings $[16,17,21]$. The higher incidence of cardiac systolic dysfunction manifesting as atrial fibrillation, the higher prevalence of comorbidities coupled with poor cardiac reserve (which limits the compensatory response of the renin angiotensin aldosterone system following blood loss or vasodilatation) in this age group lead to poor venous return. The higher incidence of PCSM in females in our study agrees 
with findings by Srisawat et al. [22] who found women more likely to develop IOH and also to die following AKI from cardiac surgery. A larger proportion of the elderly in the study cohorts were post-menopausal women, the reduction in the renoprotection by female hormones, coupled with heightening cardiovascular risk profile of women after the first post-menopausal decade, both increased the risk of death in them.

The higher incidence of death among participants with background kidney dysfunction mirrors findings by Neugaten et al. [23]. Chronic kidney disease is associate with poor cardiovascular outcome, same with heart failure. The occurrence of the cardiorenal syndrome (with or without other comorbidities) in these patients prior to, during, or even post-surgery therefore synergistically worsens the risk of death in them [24].

Participants who had emergency surgery were more likely to die, similar to previous findings [25]. The likelihood of achieving hemodynamic stability prior to induction of anesthesia in them was low, and this increases the risk of intra and post-operative complications. Patients with lower MAP prior to induction of anesthesia were more likely to die and this is in agreement with previous studies [26]. A low pre induction MAP could result from overzealous blood pressure control, poor cardiac reserve, and atrial fibrillation, conditions that are commonly found in the elderly and in advance cardiac disease, with compromised cardiac output, ejection fraction and venous return. Intraoperative use of vasopressors and inotropes (markers of moderate to severe $\mathrm{IOH}$ ) was associated with increased risk of death. The pathophysiologic mechanism of ischemic-reperfusion (IR) injury is well played out during the alternation between the ischemic and reperfusion phases, and the release of inducible nitric oxide (iNO), suppression of endothelial form of $\mathrm{NO}(\mathrm{eNO})$ and release of cytotoxic calcium ions under the inflammatory cascade eventually cumulate in cell death [27].

The higher mortality rate amongst cohorts who had combined CABG and valve surgeries compared to those who had CABG alone, mirrors findings from a previous study [28]. Our cohorts who had CABG were older and were expected to have higher episodes of atrial fibrillation, lower albumin and more comorbidities. We infer that the lower death rate in CABG would be related to the relatively higher hemodynamic instability associated with valve dysfunction coupled with greater reductions in the cardiac output (CO), and ejection fraction (EF). CABG is commonly done, at times, as a prelude to more complex open heart surgeries, particularly in patients not very fit for definitive surgeries. The higher incidence of hypobicarbonatemia and elevated anion gap in cohorts with combined $\mathrm{CABG}$ and valve surgeries compared with CABG alone, is highly suggestive of worse cardiovascular dysfunction and associated functional decline in kidney function in these cohorts, hence worse clinical outcome in them [29].

Hyponatremia was associated with a poor outcome in the cohorts and this is in agreement with findings in previous studies [21]. Hyponatremia is commoner with the aged, females, advance heart failure and severe chronic kidney disease. The effect of hyponatremia on the osmotic changes in the brain parenchymal is known to negatively affect the cognitive, sensory and motor function of the central nervous system and could progress to demyelinating and degenerative brain diseases which could worsen patients' quality of life (QOL), and increase morbidity and mortality [30]. Hypoalbuminemia, a common finding in these cohorts compared to the general population, worsens hyponatremia by stimulating antidiuretic hormone (ADH) release, hence it is a common complication in these patients [7,30]. The hemodilution from $\mathrm{ADH}$ activity could also worsen the anemia in these patients, as it could also results from the cardiopulmonary bypass procedure [8]. Because of the hemodynamics of blood pressure control involving the kidneys, heart and the vasculature, many of our cohorts had MODS and tended to present worse clinical outcome compared to non-cardiac surgeries [17]. This could also explain the higher risk of death in cohorts who underwent both CABG and valve surgery among the participants. The higher incidences of elevated anion gap and hypoalbuminemia in cohorts with combined CABG and valve surgery attest to the greater morbidity and, the poor treatment outcome that was seen in them.

\section{LIMITATIONS}

Limitations encountered in our study included its retrospective design, particularly as the chronicity of kidney disease could not be determined. Death in this study was studied by its association and not by its casual relationships. Our study was single center, and objective assessment of participants QOL was not studied. Some data on the anthropometry were incomplete hence it was not analyzed. We didn't assess the impact of the different resuscitation and maintenance fluid on mortality same as we didn't determine the impact of the individual anesthetic agent on treatment outcome.

\section{CONCLUSION}

The incidence of intraoperative hypotension and post op mortality were $86.30 \%$ and $2.64 \%$, similar to findings in advanced settings. Aging, particularly in post-menopausal women, hyponatremia and background kidney dysfunction heightened mortality risk. Death in cardiac surgery was likely in emergency surgeries, low preoperative MAP, surgeries lasting $>3$ hours, combined CABG and valve surgeries, IOH with intraoperative use of vasopressors and inotropes. Independent predictors of post cardiac surgery mortality were aging, background kidney dysfunction and comorbidities. 


\section{AUTHORS' CONTRIBUTION}

Peter K. Uduagbamen: Conceptualization and design of paper.

Peter K. Uduagbamen, Tomiwa A. Omokore: Collection of data.

Peter K. Uduagbamen, Michael Sanusi, Olumide B. Udom, Osaze Ehioghae: Data analysis and interpretation.

Peter K. Uduagbamen: Manuscript drafting.

Peter K. Uduagbamen, Michael Sanusi, Olumide B. Udom, Sule I. Ahmed: Manuscript writing.

Peter K. Uduagbamen, Michael Sanusi, Olumide B. Udom, Sule I. Ahmed: Intellectual critical review.

All authors read and approved the final manuscript before submission.

\section{CONFLICT OF INTEREST}

Declared none.

\section{ACKNOWLEDGEMENTS}

We appreciate the staffs and supporting staffs of Tristate Heart and Vascular center for their support during the study.

\section{REFERENCES}

[1] Sanagou M, Wofe R, Forbes A, Reid CM. Hospital level associations with 30-day patient mortality after cardiac surgery: A tutorial on the application and interpretation of marginal and multilevel logistic regression. BMC Med Res Methodol 2012; 12: 28. DOI: 10.1186/1471-2288-12-28

[2] Schwarze ML, Redmann AJ, Alexander GC, Brasel KJ. Surgeons expect patients to buy in to postoperative life support preoperatively: Results of a national survey. Crit Care Med 2013; 41: 1-8. DOI: 10.1097/CCM.0b013e31826a4650

[3] Hein OV, Birnbaum J, Wernecke K, England M, Konertz W, Spies C. Prolonged intensive care unit stay in cardiac surgery: Risk factors and long-term survival. Ann Thorac Surg 2006; 81(3): 880-5. DOI: 10.1016/j.athoracsur.2005.09.077

[4] Ahuja S, Mascha EJ, Yang D, et al. Associations of intraoperative radial arterial systolic, diastolic, mean, and pulse pressures with myocardial and acute kidney injury after noncardiac surgery: A retrospective cohort analysis. Anesthesiology 2020; 132: 291-306. DOI: 10.1097/ALN.0000000000003048

[5] Williams TA, Ho KM, Dobb GJ, Finn JC, Knuiman M, Webb SAR. Effect of length of stay in intensive care unit on hospital and long-term mortality of critically ill adult patients. $\mathrm{Br} \mathrm{J}$ Anaesth 2010; 104(4): 459-64. DOI: 10.1093/bja/aeq025

[6] Raji YR, Ajayi SO, Ademola AF, et al. Acute kidney injury among adult patients undergoing major surgery in a tertiary hospital in Nigeria. Clin Kidney J 2018; 11(4): 443-9. DOI: $10.1093 / \mathrm{ckj} / \mathrm{sfx} 144$
[7] Weaving G, Batstone GF, Jones RG. Age and sex variation in serum albumin concentration: An observational study. Ann Clin Biochem 2016: 53(Part 1): 106-11. DOI: $10.1177 / 0004563215593561$

[8] Vercaemst L. Hemolysis in cardiac surgery patients undergoing cardiopulmonary bypass: A review in search of a treatment algorithm. J Extra Corpor Technol 2008; 40(4): 257-67.

[9] Hosmer DW, Lameshow S. Applied Logistic Regression. $2^{\text {nd }}$ ed. Wiley: New York N.Y. 2000; p. 95. DOI: 10.1002/0471722146

[10] Shah NJ, Mentz G, Kheterpal S. The incidence of intraoperative hypotension in moderate to high risk patients undergoing non-cardiac surgery: A retrospective multicenter observational analysis. J Clin Anesth 2020; 66: 109961. DOI: 10.1016/j.jclinane.2020.109961

[11] Bijker JB, van Klei WA, Kappen TH, van Wolfswinkel L, Moons KGM, Kalkman CJ. Incidence of intraoperative hypotension as a function of the chosen definition: Literature definitions applied to a retrospective cohort using automated data collection. Anesthesiology 2007; 107(2): 213-20. DOI: 10.1097/01.anes.0000270724.40897.8e

[12] Saugel B, Cecconi M, Hajjar LA. Noninvasive cardiac output monitoring in cardiothoracic surgery patients: Available methods and future directions. J Cardiothorac Vasc Anesth 2019; 33(6): 1742-52. DOI: 10.1053/j.jvca.2018.06.012

[13] Shahian DM, O'Brien SM, Filardo G, et al. The Society of Thoracic Surgeons 2008 cardiac surgery risk models: Part 1coronary artery bypass grafting surgery. Ann Thorac Surg 2009; $88(1 \quad$ Suppl): S2-22. DOI: 10.1016/j.athoracsur.2009.05.053

[14] O'Brien SM, Shahian DM, Filardo G, et al. The Society of Thoracic Surgeons 2008 cardiac surgery risk models: Part 2isolated valve surgery. Ann Thorac Surg 2009; 88(1 Suppl): S23-42. DOI: 10.1016/j.athoracsur.2009.05.056

[15] Mazzeffi M, Zivot J, Buchman T, Halkos M. In-hospital mortality after cardiac surgery: patient characteristics, timing, and association with postoperative length of intensive care unit and hospital stay. Ann Thorac Surg 2014; 97(4): 1220-5. DOI: 10.1016/j.athoracsur.2013.10.040

[16] Ackland GL, Brudney CS, Cecconi M, et al. Perioperative Quality Initiative consensus statement on the physiology of arterial blood pressure control in perioperative medicine. $\mathrm{Br} \mathrm{J}$ Anaesth 2019; 122(5): 542-51. DOI: 10.1016/j.bja.2019.01.011

[17] Nashef SA, Roques F, Sharples LD, et al. EUROSCORE II. Eur J Cardio-Thoracic Surg 2012; 41(4): 734-45. DOI: 10.1093/ejcts/ezs043

[18] Uduagbamen PK, Oyelese AT, Alalade BA, Nwogbe IC, Ofoh CJ. Serum sodium: Pattern, determinants and correlates in 
nigerians with hypertension and chronic kidney disease-a comparative study. Clin Nephrol Res 2021; 5(5): 4-11.

[19] Lackland DT. Racial differences in hypertension: implications for high blood pressure management. Am J Med Sci 2014; 348(2): 135-8. DOI: 10.1097/MAJ.0000000000000308

[20] Nadkarni GN, Galarneau G, Ellis SB, et al. Apolipoprotein L1 variants and blood pressure traits in African Americans. J Am Coll Cardiol 2017; 69(12): 1564-74. DOI: 10.1016/j.jacc.2017.01.040

[21] Uduagbamen PK, Sanusi M, Udom OB, et al. Pre-Operative hyponatremia in a high dependency cardiovascular surgical center of a tertiary health facility in Nigeria: Risk factors, prevalence, clinical correlates and treatment outcome. A Retrospective Cohort Study. O J Int Med 2020; 10(3): 288-301. DOI: 10.4236/ojim.2020.103030

[22] Srisawat N, Sileanu FE, Murugan R, et al. Variation in risk and mortality of acute kidney injury in critically ill patients: A multicenter study. Am J Nephrol 2015; 41(1): 81-8. DOI: $10.1159 / 000371748$

[23] Kidney International. KDIGO Clinical Practice Guideline for Acute Kidney Injury. Kidney Int 2012; 2(Suppl 1): 1-138. Available at: https://kdigo.org/wp-content/uploads/2016/10/KDIGO-2012-AKI-Guideline-English.pdf DOI: 10.1038/kisup.2012.1

[24] Neugarten J, Sandilya S, Singh B, Golestaneh L. Sex and the risk of AKI following cardio-thoracic surgery: A meta-analysis. Clin J Am Soc Nephrol 2016; 11(12): 2113-22. DOI:

\subsection{5/CJN.03340316}

[25] Vogt A, Grube E, Glunz HG, et al. Determinants of mortality after cardiac surgery: Results of the registry of the Arbeitsgemeinschaft Leitender Kardiologischer Krankenhausarzte (ALKK) on 10525 patients. Eur Heart J 2000; 21(1): 28-32. DOI: 10.1053/euhj.1999.1634

[26] Bashour CA, Yared JP, Ryan TA, et al. Long-term survival and functional capacity in cardiac surgery patients after prolonged intensive care. Crit Care Med 2000; 28(12): 3847-53. DOI: 10.1097/00003246-200012000-00018

[27] Lloyd CB, Nietert PJ, Silvestri GA. Intensive care decision making in the seriously ill and elderly. Crit Care Med 2004; 32(3): 649-54. DOI: 10.1097/01.CCM.0000115636.29294.2F

[28] Sun LY, Eddeen AB, Mesana TG. Disability-free survival after major cardiac surgery: A population-based retrospective cohort study. CMAJ Open. 2021; 9(2): E384-E93. DOI: 10.9778/cmajo.20200096

[29] Uduagbamen PK, Sanusi M, Udom OB, Salami OF, Adebajo $\mathrm{AD}$, Alao OJ. Preoperative metabolic acidosis in a cardiovascular surgical intensive care unit: Risk factors, clinical correlates and outcome. World J Cardiovasc Surg 2020; 10(11): 226-41 DOI: 10.4236/wjcs.2020.1011025

[30] Naka T, Kohagura K, Kochi M, Ohya Y. Hyponatremia and mortality among very elderly residents in a geriatric health service facility. Clin Exp Nephrol 2018; 22(6): 1404-10. DOI: 10.1007/s10157-018-1607-x 